\title{
"EL DON DE DAR VIDA": ANÁLISIS DE LA PRODUCGIÓN DE LA MUJER COMO PERSONA EN \\ CULTURAS HÍBRIDAS
}

\author{
"THE GIFT OF GIVING LIFE": ANALYSIS OF \\ THE PRODUCTION OF WOMEN AS PEOPLE IN \\ HYBRID SOCIETIES
}

\author{
Karla Alejandra CONTRERAS TinOCo* \\ Universidad de Guadalajara \\ Liliana Ibeth CASTAÑEDA RENTERÍA \\ Universidad de Guadalajara
}

Resumen: En este ensayo respondemos a la pregunta: ¿Qué posibilidades, obstáculos y tensiones ofrece "el don de dar vida" a la producción de la mujer como persona en México?, para ello analizamos una expresión común y de uso popular en México: "el don de dar vida". Identificamos que la expresión tiene similitudes, aunque también diferencias con "el don" del que habló Marcel Mauss. Una de las diferencias es que actualmente la expresión "el don de dar vida" se usa en las culturas híbridas. Mientras el don del que habla Mauss es propio de sociedades colectivistas. En las conclusiones presentamos el porqué de estas diferencias, y los efectos que generan para la producción del sujeto mujer.

\footnotetext{
* Profesora e Investigadora del Centro Universitario de Tonalá, Universidad de Guadalajara. Dirección: Av. 555 Ejido San José Tateposco, Nuevo Periférico Oriente, 45425, Tonalá, Jalisco, México. Correo: karla.ctinoco@academicos.udg.mx.

${ }^{* *}$ Profesora e Investigadora del Centro Universitario de la Ciénega, Universidad de Guadalajara. Dirección postal: liliana.castaneda@cuci.udg.mx
} 
Palabras Clave: El don; Mujeres; Culturas Hibridas; Persona; Individuo

Авsтract: In this essay, we answer the question: What possibilities, obstacles and tensions does "the gift of giving life" offer to the production of women as persons in Mexico? For this, we analyzed a common and popular expression in Mexico: "the gift of giving life". We identified that the expression had similarities and differences with "the gift" of Marcel Mauss. One of the differences is that currently the expression "the gift of giving life" is used in hybrid cultures while "the gift" of Mauss is typical in collectivist societies. In the conclusions, we present the reason for these differences and their effects on the production of women.

KeYwords: The Gift; Women; Hybrid Cultures; Person; Individual

\section{Introducción}

La maternidad se ha significado como la piedra angular de la feminidad. La posibilidad de concebir un hijo o hija y parirlo vivo, es considerado por muchas mujeres como la forma de constituirse como una mujer plena, lo que es producto y al mismo tiempo reproduce la idea de la existencia de un destino natural para los cuerpos femeninos.

En México, se usa con frecuencia la expresión "el don de dar vida”, que hace referencia a la posibilidad corporal de la que son poseedoras las mujeres y que las distingue de los hombres. La expresión se puede escuchar tanto en la jerga popular como en distintos medios de comunicación. Un ejemplo de la actualidad de la frase es su uso en internet. Se puede encontrar que, en sitios web consultados por mujeres embarazadas y madres para orientarse acerca de los procesos que vivirán durante el embarazo (entendido como un proceso amplio que incorpora también el parto) y los primeros años de crianza del infante, es común el uso de la frase "el don de dar vida".

Por ejemplo, en el sitio web Pinterest se puede leer: "ser mujer es maravilloso porque tenemos el don de dar vida, y eso es lo más grande del mundo" (https:// www.pinterest.com.mx/pin/350295677247120884/). También en el sitio de internet llamado "EresMamá" se puede leer lo siguiente: 
Estar embarazada es recibir el don de dar vida: Cuando una mujer sabe que está embarazada puede estar segura que fue bendecida por la naturaleza. A partir de ahí, no hay quien le quite la gracia de contar entre las muchas procreadoras que se encargaran de la prevalencia de su especie (ehttps://eresmama.com/estarembarazada-recibir-don-dar-vida/).

La expresión "el don de dar vida" se refiere a un regalo que han recibido algunas mujeres de la naturaleza y de Dios y que consiste en poder gestar y parir. Este regalo se signa en el cuerpo y debiera ser aceptado con alegría y ternura por parte de las mujeres. Esto debido a que está envuelto de moralismos y relacionado con mandatos sociales de género que asumen que la maternidad es el núcleo fundante de la identidad femenina y generador de felicidad, auto-realización y satisfacción para las mujeres (Ávila, 2005; Gillian, 2011). Tan así que, a las mujeres que deciden no tener hijos se les cuestiona, se les recrimina, se les presiona para que los tengan o se les mira con sospecha (Anzorena y Yáñez, 2013; Gillian, 2011) y las que no pueden tener hijos por impedimentos biológicos despliegan largos y costosos procedimientos de reproducción asistida para lograrlo (Imaz, 2007; Lamas, 2017) y en las ocasiones que no se logra "dar vida" se vive como un padecimiento que provoca sufrimiento (Arroyo y Castańeda, 2021). De tal modo que, "el don de dar vida", se convierte en un privilegio, una responsabilidad, una obligación y un modo de distinción frente a los hombres y otras mujeres que no pueden tener hijos y a las cuales no pocas veces se les considera como incompletas.

En vista de lo frecuente que es pensar la reproducción y gestación como un don, lo cual se ve condensado en la expresión "el don de dar vida”, surgió el interés por contrastar el don de la teoría de Mauss y el uso de la expresión "el don de dar vida”. En primera instancia nos interesó saber si el significado de la palabra don era el mismo en ambos usos o si había una resemantización del término en el uso que se le adjudica en la cultura mexicana. De acuerdo con Oxford Languages (2021) la palabra don se refiere a un regalo, dádiva o presente (material o simbólico) que se recibe de una otredad o de un ser superior.

En segundo término, nos interesó porque identificamos que Mauss (1971) en su obra "Sociología y Antropología" señaló que el don puede ser interpretado desde una dimensión espiritual. El autor postuló que las tribus daban regalos u ofrendas a los dioses y a la naturaleza, así como recibían regalos de estos. En ese sentido, en México coloquialmente se habla del "don de dar vida" como un regalo o privilegio que han recibido las mujeres de Dios y la naturaleza para ser 
creadoras de vida. Este regalo no le ha sido otorgado a los hombres y justo por ello se traduce en el núcleo de la feminidad.

Otra de las razones que nos motivó a contrastar la teoría del don maussiana con la expresión "el don de dar vida" fue que consideramos que este contraste nos ofrecía la posibilidad de analizar la Teoría del don en la temática de la reproducción y desde una perspectiva de género, ya que la frase del "don de dar vida" solo es usada en y hacia mujeres en edad reproductiva. En ese sentido, conviene señalar que identificamos que, tal como lo afirma Comas-d'Argemir (2017), la teoría del don ha sido objeto de bastante investigación y reflexión en la Antropología y en la Sociología, tanto por teóricos clásicos (Lévi-Strauss, 1987; Sahlins, 1977, Polany, 1976) como por autores contemporáneos (Godelier, 2000; Scribano, 2014; Hart, 2007), sin embargo, hay todavía una ausencia de interpretaciones del don desde una perspectiva de género. Al respecto, destaca el trabajo de Strahtern (1988), quien señala que el comportamiento de los sujetos siempre está generizado y que, por tanto, la capacidad de dar regalos es diferencial entre hombres y mujeres y está relacionada con temas como el poder y el orden social de género. Asimismo, se encuentra el trabajo de Comas-d'Argemir (2017), quien se cuestiona cómo el don y la reciprocidad están generizados en su propia naturaleza. La autora realiza una investigación acerca del trabajo de cuidados interpretado como don, como reciprocidad y como mercancía. Un aspecto clave en el trabajo de la autora es que interpreta el don desde una dimensión moral que es coherente con las responsabilidades de cuidados que han sido interpretadas desde discursos amorosos, morales y éticos y que recaen principalmente en las mujeres. Para la autora el trabajo de cuidados visto como un don es fundamental para explicar la creación, modelamiento y mantenimiento de los vínculos sociales. Si bien el trabajo de Comas-d'Argemir (2017) es relevante para mostrar como "el cuidado tiene una dimensión social y material, no solo familiar y personal” (p. 20) y para evidenciar la necesidad de hacer interpretaciones del don con una perspectiva de género en arenas como la reproducción la autora no analiza el proceso de gestación, sino que, se enfoca en los cuidados. En ese sentido, consideramos que este trabajo es un aporte a este vacío.

Por lo expuesto, en este trabajo partimos de las preguntas, ¿Qué similitudes y diferencias hay en el uso de la expresión "el don de dar vida" y el don teorizado por Mauss? ¿Qué posibilidades, obstáculos y tensiones ofrece "el don de dar vida" a la producción de la mujer como persona en México? Partimos de la hipótesis de que "el don de dar vida", es una frase que es similar, en algunas cosas, al "don" del que habló Mauss. Sin embargo, también, guarda diferencias que permiten 
problematizar las tensiones vividas por los sujetos femeninos en tanto individuos y personas derivadas del modo en que el género configura las identidades y subjetividades. Sostenemos que la diferencia más importante es que el don en Mauss se efectuaba en sociedades colectivistas, mientras que en el México actual operan otro tipo de sociedades más híbridas (García-Canclini, 1997). Esto justamente genera que "el don de dar vida" tenga un particular sentido, efecto y significado para y en la vida de las mujeres.

En particular pues, en este trabajo tenemos el objetivo de reflexionar acerca de las implicaciones del uso de la expresión "el don de dar vida" para la producción del sujeto mujer. El trabajo está organizado de la siguiente manera, a esta introducción le sigue la sección primera en la que describimos los usos, características y momentos en que se usa la frase "el don de dar vida". En la segunda sección, comparamos la oración "el don de dar vida" con el don, concepto descrito y ampliamente teorizado por Marcel Mauss (1971). El apartado tres, es una reflexión y análisis producto de la comparación entre el don de Mauss y "del don de dar vida". Finalmente, se realizan unas breves y preliminares reflexiones finales.

\section{El uso de la frase del don de dar vida en México}

El vínculo entre la identidad de género femenina y la maternidad es profundo (Ávila, 2005; Palomar, 2009; Castañeda, 2016). En trabajos anteriores hemos mostrado la manera en que la feminidad se configura a partir de la capacidad reproductiva de los cuerpos de mujer, pero además trasciende los cuerpos y se constituye como un conjunto de prácticas del cuidado de los otros que parece incluir el abandono de sí, idea que se sintetiza en el "ser para los otros" cuya manifestación máxima es justo la entrega de las mujeres al cuidado de los hijos e hijas (Castañeda, 2016; Castañeda y Contreras, 2017; Castañeda y Contreras, 2019).

En este sentido la maternidad en cuanto modelo de lo femenino se instaura como un mandato de género al mismo tiempo que como un "regalo" o "privilegio" de las mujeres. Con la expresión "el don de dar vida" en México se hace alusión, al menos, a tres características: La primera cualidad es que este don solamente es posible para las mujeres. Si bien los hombres también tienen hijos, ellos no serían portadores del "don de dar vida" ¿qué los hace diferentes?, el que ellos no paren. La segunda particularidad radica en que el don es una cualidad imaginada que se fundamenta en un argumento biológico y signado en el cuerpo. 
Cuando se habla del "don de dar vida" se hace referencia solamente a mujeres que están en edad reproductiva y en condiciones de salud y corporales óptimas para albergar en su vientre durante nueve meses a otro ser humano y luego parirlo vivo. Finalmente, una tercera propiedad "del don de dar vida" responde a una posibilidad o bendición que se ha recibido de un ser celestial o de la madre naturaleza, y, que permite dar continuidad a la especie humana, así como consolidar algunos imaginarios de familia.

El uso de esta frase también permite socializar y reproducir la idea en las mujeres de lo positivo y privilegiado que es tener la oportunidad de dar vida a otro ser; es por esto que tanto hombres como mujeres hablan del don como un regalo, como un compromiso y un destino del "ser mujer". Además, si se hace un análisis más pormenorizado de "el don de dar vida" se puede identificar que este don viene acompañado de responsabilidades sociales hacia las mujeres-madres. Estos compromisos no son contractuales sino simbólicos, morales, religiosos e implícitos. Algunas de estas obligaciones serían desear, procrear, parir, cuidar, proveer y amar al nuevo ser, el infante (Vigeti-Finzi,1998; Palomar, 2007) sobre todas las cosas.

Cuando estas obligaciones no se cumplimentan de manera óptima se pierde prestigio social y se reciben sanciones, mediante etiquetas como "la mala madre" o "la madre egoísta" (Montecino, 2007). Por el contrario, cuando la mujer que ha dado vida logra responder a estas normativas y obligaciones sociales recibe reconocimiento, aceptación y adquiere un nuevo sitio social en tanto mujer. En este sentido, Luna (2009) asegura que para las mujeres el "ser madres" fue, durante muchos años, lo que justificaba que las mujeres votaran o fueran consideradas como ciudadanas con derechos plenos ante los gobiernos Latinoamericanos, debido al maternalismo que propugnaba que las mujeres eran las educadoras y cuidadoras de "los hijos de la nación" por lo que había que cuidar de éstas.

"El don de dar vida" y la maternidad son expresiones próximas, y sobre éstas Berrio (2013) nos dice que en los pueblos indígenas de México:

A través de la maternidad y la paternidad se ponen en juego no sólo los deseos y decisiones individuales de hombres y mujeres sino también la posibilidad de acceder a un lugar de reconocimiento y legitimidad en la estructura social. En estas comunidades, hombres y mujeres se "vuelven adultos sociales" con derechos, a través de la reproducción biológica y los procesos de crianza derivados de ello (Berrio, 2013: 21). 
Tal como lo postula Berrio (2013), la posibilidad de dar vida otorga a los sujetos cierto status, prestigio y reconocimiento. El "don de dar vida" provee de sentido la existencia de un cuerpo de hembra capaz de gestar y parir a otro y coloca a la mujer que encarna ese cuerpo en una posición pública de reconocimiento y en ocasiones, afirmación propia de la máxima feminidad. Es por lo anterior que consideramos que la frase "el don de dar vida" resulta potente para explicar, por ejemplo: ¿qué se da cuando se da vida? O bien ¿cuál es la recompensa de la donación?

\section{Transitando entre la frase "el don de dar vida" y el don de Marcel Mauss: divergencias y afinidades}

En esta sección, hacemos una breve relectura del don planteado por Marcel Mauss. A partir de ahí problematizamos lo que para nosotras componen algunas similitudes y diferencias entre este don y la expresión "el don de dar vida".

Marcel Mauss (1971) usó el concepto del don para referirse a los intercambios de bienes que se efectuaban en las "sociedades primitivas". Este don es un hecho social total que tiene por objeto elaborar contratos simbólicos, generar comunión, establecer alianzas, compañerismo, intimidad, cercanía, solidaridad y apoyo entre parientes, grupos, sociedades, tribus e instituciones. Entonces, en el don no son los individuos los que intercambian regalos y establecen contratos, sino que, a través de este acto ritual de intercambio de bienes se consolidan relaciones y alianzas entre familias, tribus o grupos. Así, estas instituciones - por ejemplo, la familia- toman formas especiales para expresarse y establecer vínculos. En ese sentido, Hart (2007) a partir de una revisión crítica del trabajo de Mauss sostiene que las instituciones humanas se fundamentan en la relación entre el individuo y la sociedad. Por tanto, el autor postula que el individuo está en medio de la libertad y la obligación cuando al don se refiere, es decir, el individuo debe lograr compaginar la preocupación por los demás y por sí mismo en este ejercicio de don. De modo que, tal afirma Comas-d'Argemir (2017), el don maussiano no es ni obligatorio ni voluntario, sino que es un hibrido de ambos, ya que negarse a dar o negarse a recibir equivale a negar alianzas, mostrar deslealtades a la tribú y hasta declarar la guerra entre grupos (Mauss, 1971).

Otro de los aspectos que evidencian el carácter interesado, obligatorio y hasta económico del don es que a través del mismo se preserva o accede a nuevos status dentro de los clanes, y se define y defiende lo doméstico y lo político y se 
obtiene prestigio. Por tanto, las transacciones que implica el don están regidas por la moral y la economía (Mauss, 1971).

En el don, del que habla Mauss (1971), están implicados tres momentos: $e l$ dar, el recibir y el devolver. Con el dar se pretende mantener el honor y el prestigio, y mostrar que se tiene la generosidad y la posibilidad de compartir con el otro lo propio. En el recibir, está presente un reconocimiento, y es una obligación el aceptar lo que se recibe. Los motivos para recibir son tres: 1) poseer una habilidad, característica o una cualidad excepcional, 2) tener determinada posición dentro del grupo social o comunidad, y 3) poseer o mantener relaciones entre familias o clanes.

En cuanto al devolver, es la capacidad de regresar algo de igual o superior valor a los bienes recibidos. En esta tercera condición está colocado un compromiso social en el que va de por medio el honor. Tal como señala Ricoeur (2004) para Mauss el asunto nodal no es por qué es necesario donar, sino por qué es necesario devolver. Pareciera que lo que obliga a devolver es el carácter sustituto o de prenda de restitución. De acuerdo con Ricoeur (2004) con el don se instituye una relación entre donante y donatario, donde se establece un acto mutuo de reconocimiento entre estos dos actores que se construye a través del carácter simbólico de la cosa donada.

En síntesis, los tres elementos - el dar, el recibir y el devolver-implicados en el don, permiten que los sujetos conserven un lugar y autoridad dentro de su pueblo y familia, así como con otras comunidades. Además, que genera lazos de convivencia y cercanía.

En la obra de Mauss se expone que en algunas culturas el sistema de regalos contractuales está relacionado con hechos o acontecimientos puntuales por ejemplo el matrimonio o el nacimiento de un hijo.

\subsection{De los encuentros y similitudes entre ambos dones}

Entre el don descrito por Mauss, y "el don de dar vida" identificamos algunos símiles. En ninguno de los dos dones se habla de un intercambio económico o mercantil. Más bien se hace alusión, a un proceso, ritual o situación que otorga a los sujetos reconocimiento, honor y prestigio, la base es lo que se obtiene al dar. Además, las personas en ambos dones afianzan lugares de prestigio o se posicionan 
dentro de sus comunidades, debido a su capacidad de dar (hijos, presentes, objetos). Por ejemplo, las mujeres a partir de su capacidad de dar hijos a la familia o a la patria pasan del estatus de mujer a madres, mientras que en los rituales que documentó Mauss los individuos y sus familias adquirían determinados lugares por su capacidad de participar en los rituales y de dar.

Durante muchos años las mujeres que se negaban a tener hijos fueron objeto de sanciones sociales, críticas y reclamos. De igual manera, las personas que se negaban a participar en los rituales que se llevaban en las culturas en las que ocurría el don generaban cierto tipo de desprestigio y exclusión.

Otra similitud importante entre ambos dones es que "el don de dar vida" se recibe a través de una deidad o de la naturaleza que dota a las mujeres de una capacidad biológica especial y que las distingue de los hombres. De igual forma en los análisis de Mauss, el objeto donado sí tenía explicaciones sobrenaturales, místicas, prenaturales o provenientes de deidades.

Aparte, ambos dones permiten generar lazos de reciprocidad, compañerismo, cercanía e intimidad, así como consolidar relaciones entre o dentro de instituciones (comunales, familiares, de pareja, etcétera) y grupos sociales. Por ejemplo, dentro de la institución de la familia o con los miembros de otras comunidades. Solamente que en el caso "del don de dar vida" este contrato simbólico se refuerza en la familia, y en el don de Mauss se aseguran vínculos con las sociedades, tribus e instituciones.

\subsection{De los desencuentros o diferencias}

Aún con las semejanzas que se describen en el apartado anterior, identificamos que hay múltiples diferencias entre ambos dones. En "el don de dar vida" solo las mujeres pueden ser partícipes, debido a su capacidad biológica. Mientras que, en el don al que se refiere Mauss, cualquier miembro de la comunidad que tenga relaciones entre familias, alguna habilidad o posición dentro del grupo puede participar del intercambio.

Algo más que acrecienta el contraste entre ambos dones, es que en "el don de dar vida” se habla de una condición más individual o quizá familiar pero no comunal, en tanto que el don referido por Mauss se fundamenta principalmente en lo comunal, recordemos que estos intercambios de bienes organizan relaciones y vínculos entre dos o más comunidades. 
La donación en el "don de dar vida" se materializa de dos formas: 1) en el regalar la posibilidad de vivir a un nuevo infante, 2) en el dar hijos a la familia, a la pareja o a la patria (Fregoso, 2009). Asimismo, hay que mencionar que en "el don de dar vida" no siempre se llevan a cabo todos los elementos dar, recibir $y$ devolver, al menos no como son planteados en el don del que habla Mauss. En "el don de dar vida" no siempre está presente la obligación de dar. En los últimos años se ha visto con mayor frecuencia que hay mujeres que eligen priorizar otras dimensiones de su proyecto de vida, por ejemplo, la carrera profesional y por ello eligen o se convierten en "no-madres" (Castañeda, 2016). Estas mujeres rechazan la posibilidad de dar vida, de darse para dar. Y aquí quizá está una de las diferencias más importantes. Mientras en Mauss el don se da, en el "don de dar vida" la donación implica donarse a sí misma, y en las sociedades actuales promotoras de fuertes procesos de individualización, puede no ser tan claro ni satisfactorio lo que se puede recibir.

En este sentido, trabajos como el de Fregoso (2009) muestran como las mujeres a partir de "ser madres" fueron ganando terreno como sujetos de derechos sociales y se fueron haciendo portadoras de reconocimiento social y poder dentro de los gobiernos locales o de sus núcleos familiares, lo cual se podría considerar como el deber de devolver del que habla Mauss (1971); por otro lado, es importante considerar que no todas las mujeres-madres reciben status, honor o reconocimiento dentro de sus comunidades o familias, ya que cuando el embarazo y/o maternidad ocurren fuera de la unión de pareja, en etapas tildadas como inadecuadas, tales como la adolescencia o en condiciones particulares (discapacidad, por ejemplo), más que considerarse como una situación que otorga prestigio genera sanciones.

En resumen, como se pudo observar en esta sección, si bien existen algunas similitudes entre el don del que habló Mauss y la expresión coloquial "el don de dar vida", también hay bastantes diferencias. De estas diferencias, destaca que el don de Mauss se refiere a una práctica -donación- de comunidad que afianza y fortalece las relaciones entre comunidades. En tanto que, "el don de dar vida" implica una donación (la vida al nuevo ser), y al mismo tiempo supone que se recibió un don que lo hace posible. Lo anterior coloca a la mujer como la que recibe, la que da y cuya devolución no es clara, pues parecería lo que se devuelve es la propia afirmación de sí como portadora del don en un principio.

Aun cuando Berrio (2013) afirma que la maternidad no es una cuestión individual sino social que implica a la familia o pareja, no es que se afiancen a 
partir de los nacimientos de infantes lazos entre ciudades o comunidades. Lo que sí ocurre es que sobre las mujeres recaen mandatos, responsabilidades y normativas en torno a "ser madres", sobre todo si se considera que a lo largo de la historia la maternidad se ha calificado como parte fundamental de la identidad femenina (Saletti, 2008). En ese sentido, Castañeda (2016) afirma que durante muchos años la categoría mujer se ha definido a partir de tres ejes: "el ser para otros", "el par público/privado" y "la maternidad". Lo que da cuenta del papel que representa "el don de dar vida” para la reproducción de la categoría mujer.

\section{Las razones de los usos diferenciales de los dones}

En el apartado anterior mostramos que una importante diferencia entre los dones son sus efectos comunales o individuales. Siguiendo con esa línea, en esta sección analizaremos qué genera estas diferencias. Para ello partiremos delimitando las distancias entre la sociedad del don de Mauss, y la sociedad del "don de dar vida".

Dumont (1967 [1966]) nos dice que en las sociedades tradicionales o jerárquicas -en las que se llevaba a cabo el don- prevalece una idea colectiva del hombre, en la que los roles, funciones y acciones del individuo están determinadas por un orden normativo social, en el que los deseos y felicidad del individuo son secundarios. Al respecto Mauss (1968), en su obra: Una categoría del espiritu bumano: la noción de persona y la noción del "yo", muestra que en los pueblos Zuñi la persona se piensa ligada al clan, a tal grado que el propio nombre está definido por el clan y es este nombre el que define el rol que cada individuo va a ejecutar dentro del clan.

Otro ejemplo de estas sociedades tradicionales serían las tribus del noroeste americano, quienes, de acuerdo con Mallinowski (1922), tenían establecido un sistema social y religioso que buscaba satisfacer tanto a las personas como a los grupos sociales. En las tribus del noroeste americano, la persona tiene un nombre y un apellido que es variable según la edad, etapa de la vida y función que se ocupa dentro de la organización de las familias, adquiriendo etiquetas como el guerrero, etcétera. Otros ejemplos de grupos tradicionales en los que prevalecía la idea del individuo determinado por la sociedad serían los nootk y los tingit del norte de Alaska, que se caracterizan por usar máscaras para personificar seres o tótems. O bien las colectividades de la India, donde "el yo" se concibe como 
una cosa ilusoria que siempre está ligado con el nosotros, con las clases sociales, con el orden de nacimiento y con las jerarquías y categorías (Mauss, 1968).

Por el contrario, en las denominadas sociedades modernas, igualitarias o individualistas se ha ido hablando cada vez más del individuo como una categoría personal, que olvida sus ascendentes y es capaz de desligarse de su comunidad y grupo social (Dumont, 1967 [1966]). De esta manera, el individuo contemporáneo está caracterizado por ser constructor de su propia vida, es decir, por tener la posibilidad de elegir su proyecto vital. Así el individuo se enfrenta a la obligación y posibilidad de moldear sus oportunidades, futuro, elegir su ciudad de residencia, tipo de casa, y llevar una vida independiente y separada de las relaciones (Beck y Beck-Gernsheim, 2003).

Ya desde 1968, el mismo Mauss (1968) señalaba que el individuo se comenzó a configurar con los latinos, con quienes se inaugura la noción de sujeto de derechos y ciudadano. Antes, en Atenas, se refuerza la idea de "yo individual" porque se promueve la idea del "yo moral" que es un sujeto que tiene conciencia de sí mismo, y de lo bueno y lo malo. Posteriormente con el cristianismo se posiciona la noción de la individualidad, hecha a imagen y semejanza de Dios, con esto se le da una fundamentación metafísica al carácter individual del sujeto. Finalmente, según Mauss (1968), hemos llegado a una noción de sujeto que se caracteriza por ser un individuo psicológico, que es consciente, racional y reflexivo.

A la luz de este argumento, según Da Matta (1979), en las sociedades occidentales globales y neoliberales donde, prevalece el igualitarismo, la competencia, el ser eficaz, la ideología del éxito, el egoísmo, la libertad, la noción de ser sujeto de derecho, y conforme a todas estas condiciones se configura el individuo. Si bien prevalecen derechos familiares como la patria potestad, afirman Beck y Beck-Gernsheim que "la modernidad: actúa contra, en vez de para, la cohesión familiar. Los derechos del Estado son para los individuos y no para las familias" (2003: 41).

A pesar de que pareciera sencillo delimitar la distancia y diferencia entre sistemas tradicionales -o jerárquicos- y sistemas modernos, es necesario señalar que esta división cada vez es más compleja y desdibujada. Según Da Matta (1979) hay sociedades donde se privilegian ambas formas. Por esto Da Matta afirma que en esos sistemas, en los que prevalece tanto el tradicionalismo como la modernidad, ocurre que: 
Por un lado, tenemos una moral rígida y universal de leyes o reglas impersonales que surgen con un rasgo modernizador e individualista y se ponen en práctica para someter a todos los miembros de la sociedad y por otro, la moralidad mucho más complicada de las relaciones impuestas por los lazos de familia, redes sociales, donde la relación personal y el vínculo sustantivo permite transgredir la regla (Da Matta, 1979: 222).

En un sentido similar, García-Canclini sostiene que en algunas sociedades prevalecen procesos de hibridación cultural que dan cuenta tanto de "esas mezclas "clásicas" como de los entrelazamientos entro lo tradicional y lo moderno, y entre lo cultural, lo popular y lo masivo" (1997: 111). De manera complementaria, el mismo autor asegura que, "en los últimos años, comienzan a confrontarse los modos de pensar la hibridación entre tradición y modernidad, y distintos tipos de modernidades, en América Latina y en Estados Unidos" (García-Canclini, 1997: 115). Es innegable que en México han ocurrido estos procesos de hibridación, ya que se ha visto un rápido desarrollo industrializador, la aceleración de los flujos de comunicación, las migraciones rural-urbanas, el crecimiento y mayor inserción de las mujeres a la educación superior y a los mercados de trabajo.

Sin embargo, estos impulsos no han sustituido del todo, los ideales sobre el matrimonio, la familia y los hijos. De acuerdo con Cervantes (1999), en 1970 cuando surgieron los métodos anticonceptivos se redujeron considerablemente las tasas de natalidad, pero a partir de 1982 el uso de los anticonceptivos en México mostró una disminución notable con respecto a la década anterior. Así podemos ver que, aunque se comercializó y promovió el uso de anticonceptivos, los discursos religiosos, conservadores y las propias tradiciones tuvieron impactos en el uso o desuso de dichos métodos. Esto vuelve evidente que justamente en México se dan procesos de hibridación cultural, y una de las expresiones de estos procesos es el tema del "don de dar vida" y su vínculo con la maternidad. Sobre ello Sánchez-Bringas señala que:

la maternidad, como muchos otros fenómenos sociales, se ve afectada por procesos de globalización y modernización que tienden a homogeneizar las prácticas reproductivas, pero al ser introducidos localmente, se ubican en un tejido social previamente organizado en estructuras y jerarquías (2009: 29).

De tal modo que, en sociedades híbridas como la mexicana, en las que hay una fuerte presencia de la corrupción, la desconfianza, la moral rígida, 
individualizante, la competitividad y los derechos del sujeto se ven cuestionados y sobrepasados, es común que se recurra a las redes primarias, a los vínculos, a las redes de apoyo más próximas (Da Matta, 1979). Esto permite que, tal como asegura Da Matta (1979), la casa se piense como el sitio donde es posible construir y hablar de relaciones de reciprocidad en las que se reduzca el individualismo, en las que haya complementariedad de funciones, que se tache y recrimine la competencia y el egoísmo porque son condiciones que se convierten en amenazas para la comunidad familiar. Todas estas condiciones refuerzan el valor de la familia tradicional (habitualmente heterosexual, con los hijos), pues se convierte en la posibilidad de pensar en una comunidad de solidaridad y emociones positivas.

En estas sociedades, la familia se configura como una posibilidad para que surja la persona, es decir el "yo social", el "yo comunal" que deja de lado la competitividad y el egoísmo y es capaz de ser y pensar en los otros (Da Matta, 1979). Para Da Matta (1979) la persona es la vertiente colectiva de la individualidad, se impone sobre lo individual, y esto forma parte de una cosmovisión propia de las sociedades holistas, tradicionales o jerárquicas. En la noción de la persona está la característica de que todos se conocen, tienen relaciones complementarias, usan sus relaciones para lograr jerarquías ante los otros, y para expresar bondad, caridad, reciprocidad, apoyo mutuo y relaciones sociales y afectivas sólidas entre las personas.

En ese marco, pareciera que una posibilidad -y a veces también una demanda- para que las mujeres sean personas y no individuos es "el don de dar vida", ya que al ser madres muestran capacidad de "ser para otros", amar, cuidar, compartir, reforzar y hacer "renuncias" en pos de los vínculos familiares. Justamente por esto, se validan y popularizan frases como "el don de dar vida", ya que fortalecen y reproducen el valor simbólico de la maternidad y de la crianza de infantes, y permiten asegurar la consolidación de la comunidad familiar, ese lugar donde se establece apoyo y solidaridad en medio de competencias y egoísmos sociales. Para esto se usa como recurso el socializar sobre las mujeres que "el don de dar vida” es un regalo privilegiado y exclusivo de las mujeres, construyendo así deseos maternales en éstas.

Sin embargo, para las mujeres de sociedades envueltas en procesos de hibridez cultural -como lo es la mexicana-, la situación es más compleja porque se ven sujetas a imperativos simultáneos y contradictorios, divergentes y en ocasiones irreconciliables. Por un lado, la posibilidad -deseo construido o hasta exigenciade ser individuo a través del éxito, el poder adquisitivo, la profesionalización y 
el reconocimiento público. Por el otro, el recibir reconocimiento y ser personas dentro de la familia a partir del "ser para otros" que se finca en "el don de dar vida". Las mujeres habitualmente optan por uno u otro de estos modelos, o bien en algunas ocasiones recurren a ambos, no sin tensiones, desgastes emocionales y físicos o culpas (Contreras y Castañeda, 2016).

Un ejemplo de lo anterior se puede observar en el estudio elaborado por Fuller (2001) en Santiago de Chile, donde la autora encontró que prevalecen tres modelos de ser mujer. Las que se conciben como parte de la naturaleza, como privilegiadas por la madre tierra por su posibilidad de procreación, y que por tanto centran su proyecto de vida en el ser madres. Las que entienden que la maternidad es el medio para la reproducción de la sociedad y en miras de ello se esfuerzan por criar hijos de "calidad" o de "honor" para la nación o para recibir reconocimiento. Las que privilegian un proyecto de vida individual enfatizando la autonomía, la independencia y el éxito, aunque esto implique prescindir de tener hijos. Como se puede apreciar, los dos primeros modelos están cercanos a la noción del "don de dar vida", sin embargo, representan la dificultad y la complejidad para conciliar los deseos propios de las sociedades híbridas que demandan ser individuo y persona a la vez, debido a que la demanda de la maternidad vuelve más complejo alcanzar éxito y competitividad en los espacios públicos.

En el mismo sentido, Oviedo y García (2011) encuentran en su estudio realizado en Manizales, Colombia con mujeres adolescentes embarazadas, que para éstas el embarazo es un imaginario instituido en las mujeres que funda y guía sus deseos y aspiraciones. El embarazo y la maternidad serían los procesos que les otorgan la posibilidad de configurarse como seres de madurez, reconocimiento, responsabilidad, autonomía y adultez, condiciones que les colocan en un lugar distinto al que ocupan las mujeres adolescentes sin hijos en la esfera pública, pero que les demanda, en muchas ocasiones, interrumpir o retrasar sus proyectos económicos, profesionales o laborales. Estas mujeres "se refieren al embarazo como la culminación de un logro largamente acariciado” (Oviedo y García, 2011: 935).

Tanto el trabajo de Contreras y Castañeda (2016), como el de Fuller (2001) y el de Oviedo y García (2011) dan cuenta de cómo las mujeres han tenido que ir generando estrategias y condiciones para ser reconocidas en los espacios, ya sean públicos o privados, como sujetos de derecho y de valía. Particularmente en el ámbito privado una de las acciones seguidas por las mujeres ha sido aceptar el recibir y el dar "el don de dar vida" y con él desempeñar tareas de cuidado, alimentación y educación de infantes para consolidar instituciones como la familia 
y generar lazos de comunidad. Situación que ha reproducido jerarquías y tareas diferenciadas por sexo en la familia.

Una de las razones para que las mujeres hayan tenido que realizar labores de cuidado y domésticas prioritariamente en los espacios privados es que las mujeres se han catalogado como "lo otro", frente a los hombres que han sido concebidos como individuos, debido a que históricamente han sido residentes y visibles en el espacio público (De Beauvoir, 1949). Otra de las razones, es que se piensa socialmente que las mujeres han sido dotadas por la naturaleza con la capacidad de darse, así como de cualidades como la comprensión, el amor, la paciencia, las cuales son importantes características para consolidar la institución familiar y reproducir el imaginario hegemónico de la identidad femenina.

Por tanto, es necesario cuestionar la frase del "don de dar vida", y esas supuestas cualidades femeninas, ya que en sociedades hibridas como la mexicana, y considerando que cada vez más mujeres estudian y trabajan de manera formal o informal, debiera existir el imperativo de que tanto hombres como mujeres sean personas en el escenario familiar, no solo a partir de su capacidad reproductiva o biológica, sino de su disposición a generar redes de cooperación, trabajo conjunto, solidaridad y su expresión de emociones. A la vez que ambos debieran poder acceder a ser individuos en el espacio público, en un trabajo y dentro de negociaciones que conlleven cooperación y apoyo mutuos.

Justamente por las condiciones anteriores sostener que en la familia existe complementariedad, reciprocidad y comunidad armónica, entre los sexos, tal como lo refiere Da Matta (1979), supondría asumir que no hay un todo armónico, único, originario, jerarquizado y diferenciado por sexo. Por el contrario, De Beauvoir (1949) nos recuerda que en la sociedad hay una organización que ha jerarquizado y otorgado un lugar superior a las cosas "de los hombres" y a los hombres partiendo de argumentos naturalistas o biológicos, el cual por cierto, requiere ser deconstruido y re-organizado, porque a algunos sujetos -habitualmente las mujeres- los posiciona ante condiciones de malestar, renuncias o dobles esfuerzos mientras que a otros -comúnmente los hombres- les permite vivir y experimentar el apoyo, la ayuda y la solidaridad que no reciben del espacio público.

En suma, observamos que la presencia y utilización de frases comunes como "el don de dar vida" reproducen y refuerzan un imaginario que resitúa a las mujeres en el deber de procrear y cuidar a los infantes, apelando a regalos recibidos 
de deidades o de la naturaleza, como maneras de ser personas y gozar de derechos y prestigio dentro de la familia o de la sociedad, lo cual más que aminorar las brechas de género contribuye a reproducir las nociones que afirman que la identidad femenina se fundamenta a partir de la maternidad y el ser para otros. Por el contrario sería oportuno buscar otras alternativas de vida dentro de la familia que permitan pensar en un don como lo habló Mauss, en el que no esté de por medio el dinero, el mercado, los bienes o la eficacia personal, y que tampoco esté diferenciado por sexo o que sea exclusivo de las mujeres, sino que permita la consolidación de redes de confianza, apoyo y el orden social, donde tanto hombres como mujeres tengan el deber de procrear, cuidar, y compartir la crianza de los hijos, y que en ambos se pongan en juego su posibilidad de ser persona y de recibir prestigio y reconocimiento a partir de estas acciones dentro del espacio privado.

\section{Reflexiones finales}

Hasta aquí hemos presentado cómo el uso de una frase popular, común y altamente usada en México, permite un análisis sobre un mandato social sobre las mujeres que demanda su configuración como personas - tal como lo plantea Da Matta (1979) - desde la vertiente maternal, preservando su lugar en la familia como comunidad. Esto es en sí mismo una contradicción pues, tal como lo dice Da Matta (1979), ocurre en contextos donde la calle o la vida pública no ofrece confianza, relaciones de intimidad o acuerdos de reciprocidad y que por el contrario se privilegia el individualismo.

En sociedades como la mexicana donde se apunta hacia la despersonalización, el individualismo y el éxito, es claro que existe la necesidad por ser personas, y establecer relaciones de reciprocidad, diferenciación y cercanía tal como lo describe este autor, lo cual se consigue en el escenario familiar. Sin embargo, el uso popular y cultural de la frase "del don de dar vida" más que facilitar, dificulta la elaboración de procesos de comunidad y colaboración mutuas dentro de la familia, pues resitúa a las mujeres bajo las características históricas imputadas hacia el ser mujer: "el ser para otros" y "la maternidad". Se trata pues de un imperativo sólo para las mujeres, fundado en una diferencia biológica que "libera" a los hombres que no tienen el "don de dar vida" de la obligación de recibir y devolver. Lo anterior además deja lugar para preguntas tales como: ¿qué papel tienen los hombres en la consolidación de la familia como comunidad? ¿Por qué los 
hombres no son portadores del don de dar vida? ¿Cómo configurar comunidades de apoyo, reciprocidad y confianza que no partan de la idea de los hijos, y que además tengan un alcance fuera de la casa?

Algunas implicaciones de lo anterior es la posibilidad de que las mujeres por ser portadoras de este don de dar vida sigan quedando relegadas al ámbito privado-doméstico, encargadas de la crianza, cuidado y amor de los infantes como consecuencia de su don. En la actualidad es claro que esto ya no es satisfactorio para todas las mujeres, sobre todo si consideramos las características de sociedades que han ido paulatinamente insertándose en procesos de modernización que promueven el individualismo, la igualdad, la libertad y el éxito, lo cual pudiera generar que las mujeres no deseen concebir o criar infantes. Además, hay mujeres que han logrado ser personas y escapar del individualismo y que no necesariamente lo han logrado por sus cualidades reproductivas. Estas mujeres son capaces de establecer relaciones de cercanía, de apoyo y no son egoístas. Entonces, convendría buscar diversas formas de ser pareja, familia y de establecer redes de cooperación y encuentro más allá de los hijos.

En suma, sostenemos que establecer relaciones entre personas en una cultura híbrida donde se viven procesos de desconfianza, de corrupción y de falta de empatía hacia los otros es necesario, oportuno y valioso. Sin embargo, apelar al don de dar vida, que interpela sólo al sujeto mujer no permite responsabilizar a ambos sexos de la formación de lazos de comunales, y por el contrario sostiene las dicotomías hombre/mujer, individuo/persona, naturaleza/cultura y público/ privado.

El análisis presentado además permite pensar las múltiples posibilidades de plenitud que encierra lo femenino, además de la maternidad. Y al mismo tiempo da cuenta de las transformaciones que ésta, como categoría histórica ha tenido de concebirse como destino a plantearse como una opción. De entenderse como una forma de plenitud, a cuestionar si la retribución de dar vida es lo suficientemente satisfactoria desde el proyecto personal. Lo que vemos pues, es la tensión permanente entre la individualización del sujeto femenino y la constante interpelación a la persona mujer, su vida siempre en permanente donación.

Entender las desigualdades entre hombres y mujeres a partir de lo que encierran frases como "el don de dar vida" permite mostrar las desigualdades construidas discursivamente respecto las diferencias sexuales de los cuerpos. Un don que implica el darse y el devolver, pero donde no está claro si lo que se recibe 
es equitativo a lo que se da, y donde no es claro a quién puede reclamarse tal inequidad. Sería más útil recurrir al don del que hablaba Marcel Mauss en el que ocurran procesos de dar, recibir y devolver, y en el que exista la posibilidad de que también los hombres sean participantes activos de la configuración de la familia como comunidad. Finalmente, de lo que se trata es que todos y todas, el estado y la propia comunidad, seamos parte de la reproducción de la vida tengamos o no el don de dar vida.

\section{Referencias}

Anzonera, C. \& Yañez, S. (2013). "Narrar la ambivalencia desde el cuerpo: diálogo sobre nuestras propias experiencias en torno a la 'no-maternidad". Investigaciones Feministas, 4, 221-239.

Arroyo, L. \& Castañeda, L. (2021). "Padeciendo los cuerpos: significados de las paternidades, maternidades y la familia en mujeres y hombres infértiles". Revista la Ventana, 6 (53), 39-73.

Ávila, Y. (2005). "Mujeres frente a los espejos de la maternidad: las que eligen no ser madres". Desacatos, 17, 107-126.

Berrio, L. (2013). Entre la normatividad comunitaria y las instituciones de salud. "Procesos reproductivos y salud materna en mujeres indigenas de las Costa Chica de Guerrero". Tesis de Doctorado en Ciencias Antropológicas. Universidad Autónoma Metropolitana, Ciudad de México.

Beck, U. \& Beck-Gernsheim, E. (2003). La individualización: El individualismo institucionalizado y sus consecuencias sociales y politicas. Madrid: Paidós Estado y Sociedad.

García-Canclini, N. (1997). "Culturas híbridas y estrategias comunicacionales". Estudios de culturas contemporáneas, 3 (5), 109-128.

CASTAÑEDA, L. (2016). La configuración de género en mujeres profesionistas no madres en Guadalajara, México. Tesis de Doctorado en Ciencias en Ciencias Sociales. CIESAS OCCIDENTE. Guadalajara, México.

Cervantes, A. (1999). "Políticas de población, control de fecundidad y anticoncepción en la dinámica demográfica de México". En: B. García (compiladora). Mujeres, género y población en México. (pp. 363-420). Ciudad de México: El Colegio de México. 
Comas-D’Argemir, D. (2017). "El don y la reciprocidad. Tienen género: las bases morales de los cuidados”. QuAderns-e, 22 (2), 17-32.

Contreras, K. \& Castañeda, L. (2016). “Tensiones entre el cuerpo productivo de la mujer y la normatividad de género en torno a la maternidad". Revista: Revista Latinoamericana de Estudios sobre Cuerpo, Emociones y Sociedad (RELACES), 21 (8), 80-92.

Castañeda, L. \& Contreras, K. (2017). “Apuntes para el estudio de las identidades femeninas. El desafío entre el modelo hegemónico de feminidad y las experiencias subjetivas". Intersticios Sociales, 13, 1-19.

- (2019). "Mujeres-madres que trabajan. La resignificación de la maternidad en mujeres profesionistas en Guadalajra-Mexico”. Anthropológica, 37 (43), 133-151.

Da Matta, R. (1979). Carnavales, malandros y héroes. Río de Janeiro: Zahar.

De Beauvoir, S. (1949). Le deuxième Sexe, Paris: Galimard.

Dumont, L. (1967 [1966]). Homo hierarchicus. Ensayo sobre el sistema de castas. Traducción Rafael Pérez Delgado. Madrid: Aguilar, S.A. Ediciones.

Eresmama: Consultado en: ehttps://eresmama.com/estar-embarazada-recibir-don-darvida/ [5 de enero de 2018].

Fregoso, A. (2009). "Infancia y maternidad después de la Revolución: sus imágenes y representaciones a través de un diario tapatío (1917-1943)". Comunicación y Sociedad. Nueva época, 11, 163-192.

Fuller, N. (2001). "Maternidad e identidad femenina: relatos de sus desencuentros". En: Solumn Donas. Adolescencia y juventud en América Latina (pp. 225-242.), Lima: Fondo Editorial Puc.

Gillian, C. (2011). "La voz de la mujer-no madre". Tesis de Doctorado. Universidad Iberoamericana. Ciudad de México.

Godelier, M. (2000). "Acerca de las cosas que se dan, de las cosas que se venden y de las que no hay que vender ni dar sino que hay que guardar. Una reevaluación crítica del ensayo sobre el don de Marcel Mauss". Hispania, 1 (204), 11-26.

Hart, K. (2007). "Marcel Mauss: In Pursuit of the Whole: 'A Review Essay”. Comparative Studies in Society and History, 49 (2), 473-485.

Imaz, E. (2007). Mujeres gestantes, madres en gestación. Representaciones, modelos y experiencias en el tránsito a la maternidad de mujeres Vascas Contemporáneas. País Vasco: Universidad del País Vasco. 
Lamas, M. (2017). "Postergar la maternidad: dilema individual y síntoma cultural". En: Saldaña, A., Venegas, L. y Davids, T. (coord.). ¡A Toda Madre! Una mirada multidisciplinaria a las maternidades en México (pp. 175-198). Ciudad de México: Instituto Nacional de Antropología e Historia/Editorial Itaca/Universidad de Guanajuato/Universidad de Radboud.

LÉVY-Strauss, C. (1987 [1958]). Antropología estructural. Barcelona: Paidós.

LunA, L. (2009). "Familia y maternalismo en América Latina. Siglo XX”. En: L. G. Luna, Familia y maternalismo en América Latina. Siglo XX (pp. 247-260). Salamanca: Ediciones Universidad de Salamanca.

Malinowski, B. (1922). Argonauts of the Western Pacific. Londres: Routledge and Kegan Paul.

Mauss, M. (1968). Una categoría del espiritu humano: la noción de persona y la categoría del "yo". Sociología y Antropología. Paris: Press Universitaries de Francé,

- (1971). Ensayo sobre el Don. Madrid: Editorial Tecnos.

Montecino, S. ( $\left.{ }^{4} 2007\right)$. Madres y Huachos. Alegorias del mestizaje chileno. Santiago: Sudamericana.

Oviedo, M. \& García, M. C. (2011). “El embarazo en situación de adolescencia: una impostura en la subjetividad femenina”. Revista Latinoamerica de Ciencias Sociales, Niñez y Juventud, 2 (9), 929-943.

Oxford Languages (2021). Definición de don. Consultado en: https://languages.oup. com/google-dictionary-es/ [8 de enero de 2021].

Palomar, C. (2007). "El punto ciego en la mira de los derechos reproductivos". Pensamiento Juridico feminista, 3, 1-26.

Pinterest. Consultado en: https://www.pinterest.com.mx/pin/350295677247120884/ [18 de abril de 2018].

Polany, K. (1976 [1957]). "El sistema económico como actividad institucionalizada”. En: K. Polany, C. M. Arensberg y H. W. Pearson (eds.) Comercio y mercado en los imperios antiguos (pp. 289-315). Barcelona: Labor.

Ricoeur, P. (2004). La lucha por el reconocimiento y la economía del don. Conferencia pronunciada en la UNESCO en el año 2002.

SCribano, A. (2014). "El don: entre las prácticas intersticiales y el solidarismo”. Sociologias, 16 (36), 74-103. 
SÁNChEZ-Bringas, Á. (2009). "Reflexiones metodológicas para el estudio sociocultural de la maternidad”. Perinatología y reproducción humana, 23 (4), 237-246.

Saletti, L. (2008). "Propuestas teóricas feministas en relación al concepto de maternidad". Clepsydra, 7, 169-183.

SAhlins, M. (1977[1972]). Economía de la Edad de Piedra. Madrid: Akal.

Strathern, M. (1988). The Gender of the Gift. Berkeley: University of California Press.

Veggeti-Finzi, S. (1998). "El mito de los orígenes”. En: Silvia Tuber (ed.). Figuras de la madre (pp. 72-97). Madrid: Ediciones Cátedra.

Recibido: $16 / 12 / 2019$

Aceptado: 14/9/2020

Este trabajo se encuentra bajo una licencia de Creative Commons Reconocimiento-

NoComercial-SinObraDerivada 4.0 